\title{
A CRIATIVIDADE EM EQUIPES DE DESIGN: UMA RELAÇÃO ENTRE FATORES INFLUENTES E TÉCNICAS DE GRUPOS
}

Anelise Thaler

Universidade Federal de Santa Catarina

anethaler@gmail.com

Marcele Cassol Licht

Universidade Federal de Santa Catarina

marcele.licht@gmail.com
Berenice S. Gonçalves

Universidade Federal de Santa Catarina

berenice@cce.ufsc.br

Francisco Fialho

Universidade Federal de Santa Catarina

fapfialho@gmail.com

Resumo: Este artigo tem como objetivo identificar os fatores influentes no desenvolvimento da criatividade e relacionar com técnicas que podem fomentar tais características. O propósito de estimular a criatividade visa promover atitudes inovadoras no contexto das equipes envolvidas em projetos de Design. Para isso, um referencial teórico foi construído com base em argumentos de diferentes autores. Para a captação dos fatores foi utilizado as definições apresentadas por Bergstrom (2009), em seguida foi realizado um levantamento sobre algumas técnicas para o estimulo da criatividade, demonstradas por Cybis et al., (2010). Como resultado foi possível estruturar uma síntese que relaciona os fatores com as técnicas e que poderá ser utilizada como referência para equipes de Design

Palavras-chave: Design, Criatividade, Equipes

Abstract: This article aims to identify the influential factors in the development of creativity and relate to techniques that can foster such characteristics. The purpose of stimulating creativity aims to promote innovative actions in the context of the teams involved in project design. For this, a theoretical framework was built based on arguments of different authors. To capture the factors we used the definitions presented by Bergstrom (2009), then a survey was conducted on some techniques for stimulating creativity, demonstrated by Cybis et al., (2010). As a result it was possible to structure a summary that lists the factors with the techniques and can be used as a reference for design teams.

Kee-words: Design, Creativity, Teams 


\section{INTRODUÇÃO}

De acordo com o aumento de bens e consumo, característicos do século XXI, o Design se apresenta como uma tecnologia produtiva que vem se transformando constantemente. $\mathrm{O}$ trabalho do Designer depende de informações e fatos que fazem parte da vida dos utilizadores dos produtos e serviços que foram criados para eles.

O Design exige do profissional um amplo conhecimento, não apenas técnico mas também interdisciplinar, exigência esta, adequada à complexidade do mundo atual e da quantidade de informações disponíveis.

Assim, cabe ao Designer ter um conhecimento sobre as característica humanas, criatividade que permita gerar objetos que interpelem essa natureza, conhecimentos técnicos para colocar essa criatividade em prática e a capacidade de liderança que permitam conduzir equipes de projetos em Design.

$O$ ato de conhecer é natural e dá-se por meio da observação, da assimilação de crenças, pelos sentimentos e motivações num processo dinâmico que é desenvolvido de maneira formal e informal. Ao conhecer, desvela-se a realidade e a possibilidade de ação e de controle sobre essa mesma realidade, por isso o conhecimento possui a dimensão política em termos de se ter mais poder sobre tudo o que acontece.

O pensamento criativo está presente em todos os seres humanos, sendo produto da interação entre o indivíduo, a cultura e o contexto histórico-social. A criatividade pode ser desenvolvida, no entanto necessita de determinadas condições para se manifestar. Diante da relação entre o individuo e o meio, a criatividade surge como um fenômeno que pode ser estimulado ou inibido (SILVA et al., 2015).

A criatividade é uma potência inerente ao ser humano, como afirma Jenny (2014) imaginação significa abrir os olhos e fazer descobertas, entretanto, esse tipo de descoberta exige uma mente atenta, observadora e associativa.

Em vista disso, estimular a criatividade visa promover atitudes inovadoras no contexto dos projetos de Design. Para isso esse estudo, por meio da organização de um referencial teórico, buscou captar os fatores influentes na criatividade e relacionar com técnicas de grupo que possam promover tais características.

Utilizou-se as definições apresentadas por Bergstrom (2009), como também foi realizado um levantamento sobre algumas técnicas para o estimulo da criatividade, demonstradas por Cybis et al. (2010).

Como resultado foi possível estruturar uma síntese que relaciona os fatores com as técnicas permitindo, assim, a visualização de diferentes elementos presentes durante o processo de criação. O quadro proposto como resultado, poderá ser utilizado como referência para guiar equipes envolvidas em projetos de Design.

\section{FATORES INFLUENTES DA CRIATIVIDADE}

A criatividade é uma fascinante fonte central de significado em nossas vidas. A primeira é o resultado da criatividade individual que foi reconhecido, recompensado e transmitida através da aprendizagem. Maioria das coisas interessantes e importantes são resultados da criatividade humana, diferente de outras espécies. Por meio da nossa linguagem, valores, expressões artísticas, conhecimento científico, tecnologia e criatividade os seres humanos se diferencia de outras espécies. A segunda razão que criatividade é tão fascinante é que quando estamos envolvidos sentimos a vida plenamente. A criatividade deixa resultados que aciona a riqueza e a complexidade do futuro (MIHALY, 2007). 
Siqueira (2015) argumenta que a criatividade envolve as relações existentes entre diferentes conhecimentos, a fim de gerar uma nova realidade externa, original e valiosa. Consiste na habilidade de combinar elementos, conceitos, técnicas, ferramentas e materiais com o objetivo de solucionar desafios específicos.

O autor apresenta como exemplo a invenção de Gutenberg, que combinou a prensa de uvas com os moldes de cunhar moedas para produzir seu sistema de impressão. Assim, sobre o conhecimento referente ao esmagamento de uvas, ele isolou o conceito "prensa". Sobre a cunhagem de moedas, extraiu o conceito "gravação". Ao assimilar suas observações com uma situação vivenciada, combinou-os e os transferiu para a impressão de livros.

Segundo Martínez (1997), é necessário desenvolver a potencialidade criativa do indivíduo, como expressão de seu próprio desenvolvimento. Dessa forma, torna-se relevante considerar os fatores que influenciam a criatividade ou a inibição dela.

Oliveira (2010) argumenta que os fatores influentes da criatividade são de diferentes categorias, incluindo entre eles: família, escola, ambiente de trabalho, saúde, contexto sociocultural, para citar alguns.

De acordo com a autora, os fatores relacionados ao desenvolvimento da criatividade do ser humano são apresentados inicialmente com a família; em segundo momento, no período escolar, seguindo um fluxo natural para o seu ambiente de trabalho e seu contexto sociocultural. Assim, a criatividade corresponde às necessidade do indivíduo, pois, em um mundo de mudanças constantes, o indivíduo precisa adaptar-se à situações novas.

A autora ressalta que no contexto do trabalho é relevante a construção de um ambiente favorável à criatividade, ou seja, que estimule os evolvidos a serem espontâneos, expressivos, participativos e parceiros, potencializando ações direcionadas ao crescimento pessoal e coletivo.

Segundo o autor Mihaly (2007) a criatividade resulta a partir da interação de um sistema composto por três elementos: a cultura com regras simbólicas, a pessoa que traz novidade para o domínio simbólico, e um campo de especialistas que reconhecem e validam a inovação. Esses três elementos são necessários para uma ideia criativa.

Novaes (2011), afirma ainda que ser criativo é um estado saudável da vida de um indivíduo. A disposição para ser criativo não traz benefícios decorrentes somente das inovações que promove, mas também é uma fonte de fortalecimento da autoestima, motivação e sentimento de realização pessoal.

O indivíduo criativo, por estar sempre desafiando a si mesmo, frequentemente transforma seu trabalho em uma fonte de prazer, dissociando seus resultados somente de aspectos materiais. Ao agirem desse modo, os indivíduos criativos reforçam a capacidade do autoconhecimento e aperfeiçoamento. Além disso, suas atitudes derivam ganhos para toda a sociedade (FERREIRA e REZENDE, 2013).

No contexto do Design, a criatividade é a expressão de novas ideias, sendo que a inovação é a realização das ideias novas que foram concebidas. Nessa relação, o design estabelece um elo que integra a criatividade e inovação. Desse modo, o Design promove a descoberta de oportunidades e contribui para estimular a inovação nos mais diferentes contextos projetuais (BEST, 2012).

Segundo o autor Rafael Cardoso (2013) a melhor maneira de estimular a criatividade no Design é promover o intercâmbio com as outras áreas do conhecimento, incluindo as que englobam a criação plástica, formal ou visual. 
O trabalho criativo na área do Design pode ser influenciado por diferentes aspectos. Em vista disso, o autor Bergstrom (2009) faz uma organização que refere-se aos fatores envolvidos no processo criativo, que serão apresentados a seguir:

Quadro 1 - Fatores que influenciam a criatividade.

\begin{tabular}{|c|c|}
\hline Insight & $\begin{array}{l}\text { O processo se inicia com a percepção do contexto e sobre o que se deseja. Pode } \\
\text { ser referente à criação de algo novo ou aprimoramento. }\end{array}$ \\
\hline Objetivos & $\begin{array}{l}\text { Os objetivos precisam ser claros, assim como questões do projeto para que } \\
\text { possa motivar e desafiar a equipe em busca de realizações. }\end{array}$ \\
\hline Situação & $\begin{array}{l}\text { Oferecer uma visão ampla sobre o que será projetado, como condições do } \\
\text { projeto, possibilidades e recursos disponíveis. }\end{array}$ \\
\hline Preparação & $\begin{array}{l}\text { As informações são reunidas e discutidas de modo flexível pela equipe. Intuito } \\
\text { de conectar diferentes fatos e permitir olhar para um tema sob diferentes } \\
\text { perspectivas. }\end{array}$ \\
\hline Abertura & $\begin{array}{l}\text { A equipe deve cultivar um ambiente de abertura no sentido de eliminar o } \\
\text { medo, a insegurança e as restrições que possam inibir colaborações diversas. }\end{array}$ \\
\hline Prioridades & $\begin{array}{l}\text { Diante da interação entre os indivíduos, o entusiasmo e a dedicação precisam } \\
\text { ser estimulados, assim como a boa relação entre o grupo para conduzir o } \\
\text { trabalho com fluidez. As criticas devem ter o caráter construtivo, com } \\
\text { direcionamento para o aprimoramento. }\end{array}$ \\
\hline Intervalos & $\begin{array}{l}\text { Para fomentar a criatividade é necessário valorizar o benefício de intervalos. } \\
\text { Isso permite associações diferentes quando o sujeito está distante do projeto } \\
\text { mas em um estado de contemplação que pode ocorrer em contextos muito } \\
\text { diversos. }\end{array}$ \\
\hline Truques do ofício & $\begin{array}{l}\text { A equipe pode ser estimulada a realizar a dramatização de uma situação, } \\
\text { simulando possíveis comportamentos de seus futuros usuários para observar e } \\
\text { tentar captar atitudes diferentes. }\end{array}$ \\
\hline Censura & $\begin{array}{l}\text { A censura pode ser interna ou externa. A censura interna ou autocensura inibe } \\
\text { a autoconfiança que muitas vezes impede o sujeito de manifestar uma ideia } \\
\text { valiosa para a continuidade do trabalho. A censura externa corresponde aos } \\
\text { estímulos captado a partir do meio em que o sujeito está inserido, como regras, } \\
\text { padrões e hierarquias. }\end{array}$ \\
\hline Respeito & $\begin{array}{l}\text { É necessário que os integrantes de um grupo saibam respeitar diferentes } \\
\text { papéis, contudo, o diálogo interdisciplinar pode ocorrer para ampliar as } \\
\text { possibilidades com diferentes percepções sem que para isso comprometa o } \\
\text { respeito. }\end{array}$ \\
\hline Ideia & $\begin{array}{l}\text { Os fatores anteriores impulsionam a criatividade. Após a geração de ideias é } \\
\text { preciso dar continuidade com os caminhos identificados. Assim, a ideia } \\
\text { inicialmente elaborada precisa de tratamento, e também da aceitação da } \\
\text { equipe envolvida, para a implementação do projeto. }\end{array}$ \\
\hline
\end{tabular}

Fonte: BERGSTROM (2009).

O quadro 1 evidencia diferentes aspectos ou fatores que envolvem os participantes de uma equipe de Design. Ter clareza que durante os projetos de Design atuam indivíduos com perfis variados e necessidades próprias. Assim, a valorização e estímulo da criatividade têm um papel fundamental, uma vez que pode potencializar o surgimento de ideias potenciais de seus colaboradores.

De acordo com Bergstrom, (2009), para favorecer o surgimento de boas ideias é necessário que exista uma relação, a qual o autor define como um diálogo, que ocorre em dois níveis do ser, um interior e o outro exterior. O primeiro nível, tem origem nos pensamentos do sujeito que correspondem às suas vivências, enquanto o segundo nível, refere-se a interação desse sujeito em um grupo de pessoas reunidas com o ideal de cooperação. 
O autor ainda esclarece que no processo interno atuam equacionamentos entre os pensamentos que surgem e a gestão desses pensamentos. Assim, a criatividade precisa de condições para se expressar de modo que as restrições e bloqueios sejam minimizados em grupo de trabalho. Como resultado, pode-se observar que um individuo durante seu processo criativo vivencia uma experiência de fluxo em que ele tem a sensação de que sua atenção está voltada para a atividade desenvolvida, com naturalidade rumo ao êxito.

\section{TÉCNICAS PARA ESTIMULAR A CRIATIVIDADE}

A partir do entendimento sobre criatividade, Cybis et al. (2010) apresenta algumas técnicas que podem ser utilizadas para a geração de ideias e estimulo para a criatividade, tais como Brainstorming, Card Sorting, Diagrama de afinidade, Stoyboard e Maquetes, que serão detalhadas a seguir.

1. Brainstorming: esta técnica tem como significado "tempestade de ideias" e se caracteriza como uma reunião que visa a geração de ideias em grupos. 0 grande benefício que essa técnica oferece para a criatividade está na oportunidade de desenvolver uma discussão livre em torno de um objeto de estudo a ser explorado. Como recomenda a técnica, pode ter entre 2 a 12 participantes entre eles um facilitador. Em um primeiro momento todas as ideias podem ser lançadas ao grupo sem restrições quanto ao conteúdo para que em um segundo momento seja feita uma observação crítica para a identificação de caminhos possíveis.

2. Card Sorting: Conhecida como arranjo de cartas, essa técnica propõe a criação de diferentes ideias sobre um sistema e posteriormente, o projetista convida um representante de usuário para organizar as cartas de acordo com seu modelo mental. Essa técnica, permite o diálogo entre desenvolvedores e usuários para que ocorra a integração dos discursos e assim seja possível ampliar as combinações de informações, funcionalidade, recursos e conteúdos.

3. Diagrama de afinidade: técnica utilizada entre desenvolvedores e usuários com o objetivo de realizar um levantamento de ideias e posteriormente agrupá-las seguindo semelhanças entre itens listados previamente.

4. Stoyboard: técnica de concepção utilizada para expressar ideias em forma de narrativas. As narrativas gráficas são representações feitas com desenhos que possuem detalhes sobre o fluxo de interações dos usuários com o conteúdo a ser projetado.

5. Maquetes: protótipos em papel são formas simples e eficientes de promover a geração de ideias, uma vez que permitem a criação de representações sobre um determinado aspecto da interação. Assim, possibilita a percepção cobre características sobre um contexto favorecendo a captação de requisitos de projetos. 
As técnicas apresentadas representam algumas estratégias que as equipes de Design podem fazer uso. A prática dessas atividades oportunizam condições favoráveis à expansão da criatividade do grupo de trabalho. Tais técnicas podem ser empregadas com foco na captação de oportunidades para novos produtos ou mesmo para aprimorar sistemas já existentes.

\section{PROCEDIMENTOS METODOLÓGICOS}

A partir da organização de um referencial teórico, foi possível identificar autores que abordam a criatividade em equipes de Design, tais como: Bergstrom (2009) que apresenta fatores influentes da criatividade; e, Cybis et al., (2010) que faz um levantamento sobre as principais técnicas para o estimulo da criatividade. Como resultado foi possível estruturar uma síntese que relaciona os fatores com as técnicas e que poderá ser utilizada como referência para equipes de projetos de Design.

\subsection{Resultados e discussões}

Os resultados apresentados a seguir (quadro 2) propõem uma relação entre fatores e técnicas que estimulam a criatividade em uma equipe de design.

\section{Quadro 2 - Fatores e técnicas para promover a criatividade}

\begin{tabular}{|c|c|}
\hline FATORES & TÉCNICAS \\
\hline $\begin{array}{l}\text { Insight } \\
\text { Truques do ofício } \\
\text { Situação } \\
\text { Preparação }\end{array}$ & $\begin{array}{l}\text { Brainstorming } \\
\text { Card Sorting }\end{array}$ \\
\hline $\begin{array}{l}\text { Prioridades } \\
\text { Objetivos } \\
\text { Ideia }\end{array}$ & $\begin{array}{l}\text { Diagrama de afinidade } \\
\text { Stoyboard } \\
\text { Maquetes }\end{array}$ \\
\hline $\begin{array}{l}\text { Censura, Abertura, } \\
\text { Respeito e Intervalos }\end{array}$ & $\begin{array}{l}\text { Pertence à todas as } \\
\text { técnicas }\end{array}$ \\
\hline
\end{tabular}

Fonte: Elaborado pelos autores com base nos autores consultados.

A partir do quadro 2, identifica-se que os fatores censura, abertura, respeito e intervalos são necessários durante todo o desenvolvimento de um projeto, assim pertencem à todas as técnicas.

Pode-se relacionar os fatores Insight, truques do ofício, situação e preparação com as técnicas brainstorming e card sorting, pois são destinadas à compreensão de um projeto, identificação do desafios, assim como do levantamento das possibilidades.

Os fatores prioridades, objetivos e ideia estão relacionados com as técnicas diagrama de afinidade, stoyboard e maquetes, pois correspondem aos momentos em que a equipe já possui informações suficientes sobre o projeto e necessita de um direcionamento mais objetivo para a continuidade das ideias.

A síntese, apresentada no quadro 2, oportuniza à equipe de Design visualizar fatores que interferem na criatividade do grupo e técnicas que podem estimular tais 
elementos. Além disso, torna explícito a presença de fatores que estão presentes durante todo o envolvimento presente entre os participantes de uma equipe.

\section{CONSIDERAÇÕES FINAIS}

O conhecimento dá ao designer autonomia de ação e flexibilidade. Dessa maneira, a formação de significados e ao mesmo tempo de uma prática, faz com que exista uma indissociabilidade entre a teoria e a prática, entre a ação e a reflexão. A criatividade pode contribuir para o desenvolvimento de ideias inovadoras ou mesmos para aprimorar produtos existentes.

Com o intuito de fomentar a expansão da criatividade, no contexto dos projetos que envolvem uma equipe de Design, após a identificação dos fatores descritos por Bergstrom (2009) e o levantamento sobre técnicas para promover a criatividade por Cybis et al., (2010), foi possível estruturar uma síntese.

Como resultado, a equipe de Design poderá visualizar fatores que interferem na criatividade do grupo e técnicas que podem estimular tais elementos. Além disso, evidencia a presença de fatores que estão presentes durante todo o envolvimento estabelecido entre os participantes de uma equipe.

\section{REFERÊNCIAS}

BERGSTROM, Bo. Fundamentos da Comunicação Visual. São Paulo: Rosari, 2009.

BEST, K. Fundamentos de gestão do design. Porto Alegre: Bookman, 2012.

CARDOSO, Rafael. Design para um mundo complexo. Editora Cosac Naify, 2013.

CYBIS, Walter; Richard et. al. Ergonomia e usabilidade. São Paulo: Novatec, 2010.

MARTÍNEZ, Albertina Mitjáns. A criatividade, personalidade e educação. São Paulo: Papirus, 1997.

MIHALY, Csikszentmihalyi. Creativity: Flow and the psychology of discovery and invention. HarperCollins e-books, 2007.

NOVAES, Maria Helena. Modelos interpretativos da criatividade e alternativas de atuação psicossocioeducativa. In: DEL PRETTE, Zilda Aparecida P. (Org.). Psicolo-gia Escolar e Educacional: Saúde e Qualidade de Vida, p. 69-80, Campinas: Alínea, 2011.

LUPTON, E.; PHILLIPS, J. C. Novos fundamentos do design. São Paulo: Cosac Naify, 2008.

OLIVEIRA, Zélia Maria Freire de. Fatores influentes no desenvolvimento do potencial criativo. Estudos de Psicologia. Campinas, 27(1), 83-92, janeiro - março 2010.

SAMARA, Timothy. Guia de design editorial. Porto Alegre: Bookman, 2011a.

SILVA, Josinaldo B.; Campos, Fábio; Campello, Sílvio Barreto; "Um Panorama sobre a pesquisa de criatividade no Design Gráfico", p. 993-1006 . In: . In: C. G. Spinillo; L. M. Fadel; V. T. Souto; T. B. P. Silva \& R. J. Camara (Eds). Anais do 70 Congresso Internacional de Design da Informação/Proceedings of the 7th Information Design International Conference | CIDI 2015 [Blucher Design Proceedings, num.2, vol.2]. São Paulo: Blucher, 2015. ISSN 2318-6968, ISBN: - DOI 10.5151/designpro-CIDI2015-151

SIQUEIRA, Jairo. Criatividade e inteligência. Disponível na internet em: <http://criatividadeaplicada.com/2007/01/29/42/>. Acesso em 20 de set de 2015. 